Available online on 22.06.2020 at http://jddtonline.info
Open Access to Pharmaceutical and Medical Research
unrestricted non-commercial use, provided the original work is properly cited

Open Access

Research Article

\title{
Antioxidant and hepatoprotective Potential of Coriandrum sativum L. against hepatic injury by Lambda-cyhalothrin insecticide
}

\section{DJAHRA Ali Boutlelis ${ }^{*}$, BENKADDOUR Mounia1, BENKHERARA Salah², OUAHIBA Bordjiba ${ }^{3}$}

1 El-Oued University, BES Laboratory, Fac. Natural Science and Life, 39000 El-Oued, Algeria

3 Ghardaia University, Fac of Natural Science and Life, 47000 Ghardaia, Algeria

4 University of Annaba, PBE Laboratory, Fac. Sciences / 23000Annaba, Algeria

\begin{abstract}
The objective of this study is to evaluate the antioxidant and hepatoprotective activity of aerial part and seeds of Coriandrum sativum plant against Lambda cyhalothrin insecticide. Male Wistar Albinos rats were randomly divided into control, LCT, CsA, CsS, CsS+LCT, CsA+LCT groups, after 90 days of treatments Biochemical, some oxidative stress parameters, and histopathology of liver tissue were evaluated. Total polyphenol content in aerial part and the seed extract estimated at 9.29 and $14.64 \mathrm{mg}$ EAG / mg of extract and IC 50 for an antioxidant activity equal to 19.38 and $22.62 \mathrm{mg} / \mathrm{ml}$ respectively. The obtained results revealed that rats received Lambda cyhalothrin insecticide showed a significant change in enzymes activity (AST, ALT, ALP and c-GT) and Glutathione (GSH) in liver. Meanwhile content of hepatic Malondialdehyde (MDA). Histopathology examination of liver revealed that Coriandrum sativum attenuate the incidence of liver lesions triggered by Lambda cyhalothrin intoxication. Therefore, the results of this study show that Coriandrum sativum can be proposed to protect the liver against Lambda cyhalothrin induced oxidative damage in rats, and the hepatoprotective effect might be correlated with its antioxidant and free radical scavenging effect.
\end{abstract}

Keywords: hepatoprotective, antioxidant, Coriandrum sativum L., Lambda cyhalothrin, Oxidative stress.

Article Info: Received 28 March 2020; Review Completed 02 June 2020; Accepted 09 June 2020; Available online 22 June 2020

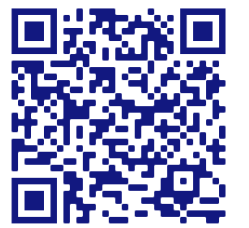

\section{Cite this article as:}

Djahra AB, Benkaddour M, Benkherara S, Ouahiba B, Antioxidant and hepatoprotective Potential of Coriandrum sativum L. against hepatic injury by Lambda-cyhalothrin insecticide, Journal of Drug Delivery and Therapeutics. 2020; 10(3-s):182188 http://dx.doi.org/10.22270/jddt.v10i3-s.4186

*Address for Correspondence:

DJAHRA Ali Boutlelis, El-Oued University, BES Laboratory, Fac. Natural Science and Life, 39000 El-Oued, Algeria

\section{INTRODUCTION}

The Algerian association of environment protection asserts that Algeria is a major consumer of pesticides; in fact 30,000 tons are spread each year. Half of agriculture production would contain these chemicals, the use of xenobiotic like pesticides induce reactive oxygen formation, reduce antioxidant enzyme and especially oxidative stress 1,2 . Pesticides cause a number of severe health effects and illnesses, but can be cured by conventional and traditional medicine; Furthermore, experimental studies ${ }^{3}$ and clinical studies 4 have shown that many medicinal plants have an antioxidant effect through their active ingredient, which exists in plant organs.

The use of natural products from medicinal plant has taken advantage of multiple interests in food, cosmetic and pharmaceutical. For their high antioxidative activity, the natural products are found many kinds of secondary metabolites such as Flavonoids, Alcaloids, Tannins. The natural substances are being extensively studied for their ISSN: 2250-1177 capacity to protect organisms and cells from damage brought on by oxidative stress, the latter being considered a cause of ageing and degenerative diseases 5 . Additionally, recent studies have suggested that natural antioxidants in complex mixtures ingested with the diet are more efficacious than pure compounds in preventing oxidative stress-related pathologies due to particular interactions and synergisms 6 .

The genus Coriandrum includes a lot of cultivated plants, the most important is coriander (Coriandrum sativum L.), and it's native to southern Europe and the western Mediterranean region. This herb widely used and growth in worldwide. It has many therapeutic virtues and use for the treatment of several diseases. The seeds are widely used for the preparation of the powder of spices, their therapeutic properties are due to the presence of active ingredients. In addition, used in the Algerian diet 7 .

In this study, we investigated the Antioxidant activity In vitro and potential hepatoprotective effects of Coriander: Coriandrum sativum areal part and seed powder in the

\section{CODEN (USA): JDDTAO}


Lambda-cyhalothrin pesticide induced hepatic damage in Wistar albinos rats.

\section{MATERIALS AND METHODS}

\subsection{Chemicals}

All chemicals were analytical grade and chemicals required for all biochemical assays were obtained from Sigma Chemicals Co., USA, and the pesticide Lambda-cyhalothrin was obtained from Nanjing Zonechem Co laboratory.

\subsection{Preparation of plant extract}

The areal part and seed of C.sativum were collected from Kouinine village, Wilaya of El-Oued, Algeria. The areal part was washed under running tap water to eliminate dust and other foreign particles and to cleanse the leaves thoroughly and shade dried for 22 days. $30 \mathrm{~g}$ of shade-dried powdered plant (areal part and seed) was extracted with $200 \mathrm{ml}$ of water. The resulting extract was filtrated through Whatman $\mathrm{N}^{\circ}$ : 1 filter paper and evaporated under reduce pressure then dried. The percentage yield of two extract was 22.6 and $11.63 \%$ for areal part and seed respectively, the two extracts were stored in refrigerator at $4 \pm 1^{\circ} \mathrm{C}$ for determination of total phenolic content and DPPH free radical scavenging assay.

\subsection{Determination of total phenolic content}

Total phenolic content were determined according to the literature ${ }^{8,9}$. Briefly, $200 \mu \mathrm{l}$ of the diluted sample was added to $1 \mathrm{ml}$ of Folin-Ciocalteu reagent. After $4 \mathrm{~min}, 800 \mu \mathrm{l}$ of saturated sodium carbonate solution (about 20\%) was added. After $2 \mathrm{~h}$ of incubation at room temperature, the absorbance of the reaction mixture was measured at 765 $\mathrm{nm}$. The same procedure was repeated to all standard gallic acid solutions $(0-500 \mu \mathrm{g} / \mathrm{ml})$ and standard curve was obtained.

\subsection{DPPH Free Radical Scavenging Assay}

The radical scavenging assay was conducted as described by 10. The DPPH solution was prepared by dissolving $2.4 \mathrm{mg}$ DPPH in $100 \mathrm{ml}$ of methanol. $25 \mu \mathrm{l}$ of extract or standard antioxidant (Ascorbic acid) were added to $975 \mu \mathrm{l}$ of DPPH solution. The mixture was shaken vigorously and incubated for $30 \mathrm{~min}$ in the dark at room temperature and the decreases in the absorbance values were measured at 515 nm. The percentage of DPPH scavenging activity was calculated using the following equation.

\%DPPH scavenging activity $=\left(\mathrm{A}_{\text {control }}-\mathrm{A}_{\text {sample }} / \mathrm{A}_{\text {control }}\right) 100$

Where $\mathrm{A}$ control is the absorbance of the control reaction mixture without the test compounds, and A sample is the absorbance of the test compounds. $\mathrm{IC}_{50}$ values, which represented the concentration of the extract that caused $50 \%$ neutralization of DPPH radicals, were calculated from the plot of inhibition percentages against concentration of the samples ${ }^{11}$.

\subsection{Experimental animals}

Male Wistar albinos rats (146 $\pm 4 \mathrm{~g}$ ) purchased from Pasteur Institute of Algeria, were used for the study. The animals were housed in large, clean, polypropylene cages and acclimated to our laboratory animal for two week before the start of the experiments. Animals were maintained in a temperature $\left(24 \pm 3^{\circ} \mathrm{C}\right), 12 \mathrm{~h}$ light/dark cycles with free access to food and tap water.

\subsection{Experimental design}

The Animals were divided into six groups of six animals per group $(n=6)$ and received their respective treatment for 90 days as follow: group 1: served as untreated control group, Group 2: received Lambda-cyhalothrin $(62.5 \mathrm{mg} / \mathrm{L}$ in drinking water), group 3 fed on seed of C.sativum diet ( $1 \%$ $\mathrm{w} / \mathrm{w})$, group 4 fed on areal part of C.sativum diet (1\% w/w), group 5: received Lambda-cyhalothrin and fed on seed of C.sativum diet. Group 6: received Lambda-cyhalothrin and fed areal part of C.sativum diet. During experience, body weight was recorded periodically during the experiment weeks.

\subsection{Calculation of relative Liver weight}

The relative liver weight was calculated according to the formula: (Rats liver weight/rats weight)*100\%.

\subsection{Blood collection and tissue homogenate}

Animals were sacrificed $24 \mathrm{~h}$ after the last dose of C.sativum. Just before sacrifice, the blood was collected and the serum was separated by centrifugation at $3000 \mathrm{rpm}$ for $5 \mathrm{~min}$ and used for biochemical estimations. The liver and was removed, washed with saline solution, weighed and divided into samples. The samples were used for preparation of histological sections and post mitochondrial supernatant (PMS).

\subsubsection{Determination of serum enzymes activity}

The activities of serum aspartate transaminase (AST), alanine transaminase (ALT), alkaline phosphatase (ALP) and Gama-glutamil transferase $(\gamma$-GT) levels were determined by using the automatic analyzer (Technicon R.A® 1000).

\subsubsection{Determination of liver homogenate parameters}

\section{- Preparation of post mitochondrial supernatant}

$0.5 \mathrm{~g}$ of the liver isolated from sacrificed animals were homogenized in chilled phosphate buffer $(0.1 \mathrm{M}, \mathrm{pH} 7.4)$ containing potassium chloride $(1.17 \%)$, the homogenate was centrifuged at $800 \mathrm{rpm}$ for 15 minutes to remove nuclear debris. The supernatant so obtained was further centrifuged at $9600 \mathrm{rpm}$ for 45 minutes at $4^{\circ} \mathrm{C}$ to get post mitochondrial supernatant (PMS) which was used as a source of enzymes.

\section{- Determination of total protein}

The total proteins in liver homogenates were determined by Coomassie Brilliant Blue G-250 methods using bovine serum albumin as the standard ${ }^{12} .0 .1 \mathrm{ml}$ of liver homogenates was transferred to $5 \mathrm{ml}$ volumetric flask and the volume adjusted with Coomassie Blue and mixed by vortex. Wait 5 minutes and the produced blue color was measured spectrophotometrically at $595 \mathrm{~nm}$.

\section{- Determination of Glutathione (GSH) content}

The assay of GSH was estimated by the method of Weckberker and Cory 13. The liver samples were homogenized in $1 \mathrm{ml}$ of EDTA $(0.02 \mathrm{M})$. The homogenate was then subjected to a deproteinization with sulfosalicylic acid (SSA) $0.25 \%$. Then $0.8 \mathrm{ml}$ homogenate was added to 0.2 $\mathrm{ml}$ of the mixture, this was vortexed and left for $15 \mathrm{~min}$ in an ice bath before centrifugation (1000 rpm for $5 \mathrm{~min}$ ). The supernatant $(0.5 \mathrm{ml})$ was supplemented with $1 \mathrm{ml}$ of TrisEDTA (0.02 M, pH 9.6) and $0.025 \mathrm{ml} \mathrm{(5-5'-dithio-} \mathrm{bis-2-}$ nitrobenzoic acid (DTNB, $0.01 \mathrm{M}$ ) and then left at room temperature for $5 \mathrm{~min}$. The optical density was measured at $412 \mathrm{~nm}$ after $5 \mathrm{~min}$. 
- Determination of Malondialdehyde (MDA) content

MDA was measured according to the method described by Quintanilha 14. The MDA reagent (trichloroacetic acid, thiobarbituric acid, and hydrochloric acid) was added to aliquots of the homogenate mixed with $2 \%(\mathrm{w} / \mathrm{v})$ ethanolic solution of butylated hydroxytoluene. Then, the mixture was heated for $15 \mathrm{~min}$ in a boiling water bath. After cooling, the precipitate was removed by centrifugation, and the absorbance was measured at $532 \mathrm{~nm}$.

\subsubsection{Histopathological evaluation}

Fresh liver tissues, which were previously trimmed to an approximately $2 \mathrm{~mm}$ thickness, were placed in plastic cassettes and fixed in $10 \%$ formalin for $24 \mathrm{~h}$. Then the paraffin sections were prepared (Automatic tissue processor, Autotechnique) and cut into $2 \mu \mathrm{m}$ thick sections in a rotary microtome. The sections were then stained with haematoxylin-eosin (H\&E) dye and examined under light microscope for histopathological changes.

\subsection{Statistical analysis}

Data from each experiment were expressed by the mean \pm and respective standard deviation (SD). The data were analyzed by Student test (software Minitab ${ }^{\circledR}$ 13). Values of $P<0.05$ were considered significant.

\section{RESULTS}

\subsection{Total phenol content}

The content of phenolic compounds in C.sativum extract determined using regression equation of calibration curve (y: 0.0082x $+0.1813, \mathrm{r}^{2}: 0.9524$ ), and expressed in gallic acid equivalents was found to be $9.29 \pm 0.156$ and $14.64 \pm 0.388$ $\mathrm{mg} \mathrm{GAE} / \mathrm{ml}$ of extract for the areal part and seed of C.sativum respectively.

\subsection{DPPH Free radical scavenging assay}

$\mathrm{DPPH}$, is free radicals used to determine the antioxidant activity of plant extracts. When a solution of DPPH (violet color) is mixed with the plant extracts that can donate a hydrogen atom, then this gives rise to the reduced form with the loss of their color (Molyneux, 2004). Table 1 show the results of DPPH scavenging activity.

Table 1: DPPH scavenging activity of seed and areal part of C.sativum.

\section{\begin{tabular}{c}
\hline $\mathrm{IC}_{50} \mu \mathrm{g} / \mathrm{mL}$ \\
Data are expressed as mean \pm SE (Standard Error), $(\mathrm{n}=3)$. \\
3.3.1. Effect of C.sativum on body weight and relative
\end{tabular} liver weight}

Table 2 shows that body weights rats within 90 days of the experimental were not affected by pesticide Lambdacyhalothrin, areal part and seed of C.sativum. However, a significant elevation of relative liver weight was seen in
Lambda-cyhalothrin treated group, indicating that Lambdacyhalothrin induced hypertrophy of these tissues. By contrast, areal part of C.sativum in combination with Lambda-cyhalothrin significantly reduced the elevated weight of liver, suggesting the possibility of C.sativum areal part to give protection against liver injury upon Lambdacyhalothrin induction.

Table 2: Effect of C.sativum extract on Initial body weight, body weight gain and relative liver.

\begin{tabular}{lccc}
\hline Group & Initial body weight $(\mathrm{g})$ & Body weight gain $(\mathrm{g} / \mathrm{d})$ & Relative Liver weight $(\%)$ \\
\hline Con & $164.5 \pm 3.84$ & $0.793 \pm 0.045$ & $2.538 \pm 0.091$ \\
LCT & $168.1 \pm 8.16$ & $0.676 \pm 0.07$ & $2.642 \pm 0.052^{*}$ \\
CsS & $164.3 \pm 3.70$ & $0.778 \pm 0.03$ & $2.421 \pm 0.045$ \\
CsA & $174.6 \pm 4.75$ & $0.783 \pm 0.056$ & $2.513 \pm 0.160$ \\
CsS+LCT & $154.2 \pm 8.23$ & $0.77 \pm 0.05$ & $2.872 \pm 0.131^{*}$ \\
CsA+LCT & $174.8 \pm 11.1$ & $0.98 \pm 0.195$ & $2.321 \pm 0.14^{\mathrm{a}}$
\end{tabular}

Con: Control. LCT: Lambda-cyhalothrin. CsS: Seed of C.sativum. CsA: Areal part of C.sativum. Results are presented as the mean \pm S.E. (Standard Error) $(\mathrm{n}=6) .{ }^{*} \mathrm{p} \leq 0.05,{ }^{* *} \mathrm{p} \leq 0.01$ and ${ }^{* * *} \mathrm{p} \leq 0.001$. ap $<0.05$ as compared with Lambda-cyhalothrin model group. bp $<0.05$ as compared with normal control group. 


\subsubsection{Effect of C.sativum on serum ALT, AST, ALP and $\gamma$ -} GT

The protective effect of C.sativum at dose level $(1 \% \mathrm{w} / \mathrm{w})$ on the Lambda-cyhalothrin-induced modification in serum ALT, AST, ALP and $\gamma$-GT levels was shown in Figure 1. A single dose of Lambda-cyhalothrin caused hepatotoxicity in rats as
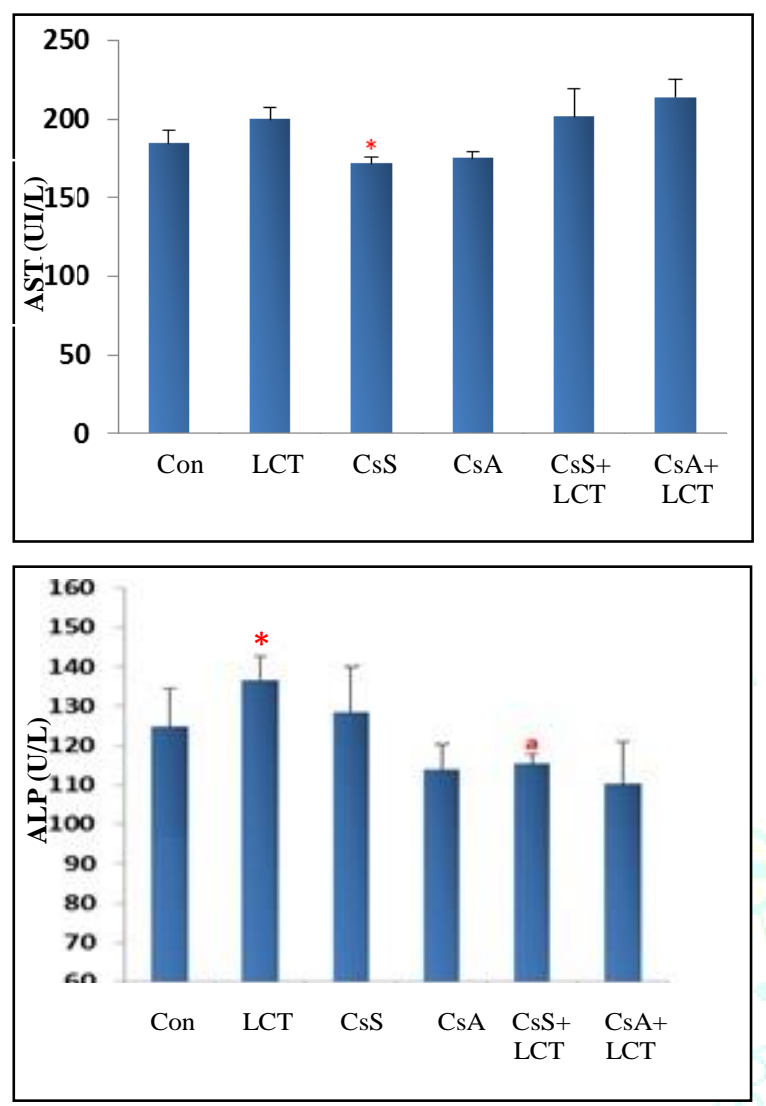

indicated by an increase in serum ALT, AST, activities after Lambda-cyhalothrin administration. Whereas, animals pretreated with C.sativum extract exhibited a significant decrease in the activities of the serum marker enzymes.

Figure 1: Effect of C.sativum extract on serum enzymes activity.

Aspartate Transaminase (AST), Alanine Transaminase (ALT), Alkaline Phosphatase (ALP), $\gamma$-Glutamyl Transpeptidase ( $\gamma$-GT).Con: Control. LCT: Lambda-cyhalothrin. CsS: Seed of C.sativum. CsA: Areal part of C.sativum. Results are presented as the mean \pm S.E. (Standard Error) (n $=6$ ). ${ }^{*} \mathrm{p} \leq 0.05,{ }^{* *} \mathrm{p} \leq 0.01$ and ${ }^{* * *} \mathrm{p} \leq 0.001$. ${ }^{\mathrm{a}} \mathrm{p}<0.05$ as compared with Lambda-cyhalothrin model group. ${ }^{\mathrm{b}} \mathrm{p}<0.05$ as compared with normal control group.

\subsubsection{Effects of C.sativum extract on GSH and MDA}

Hepatic injury induced by Lambda-cyhalothrine caused significant increase in MDA and decrease in GSH. Results C.sativum effects of on GSH and MDA in Lambda-cyhalothrin induced hepatic injury are shown in Figure 2.
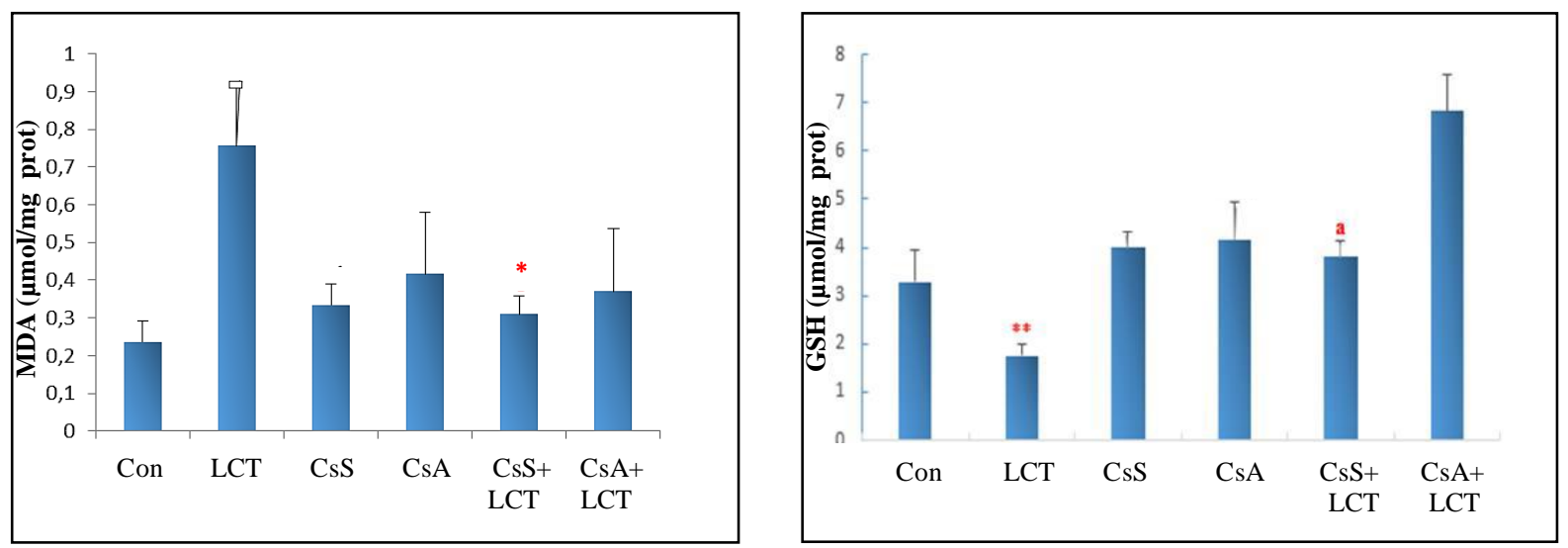

Figure 2: Effect of C.sativum extract on GSH and MDA.

Glutathione (GSH). Malondialdehyde (MDA). Con: Control. LCT: Lambda-cyhalothrin. CsS: Seed of C.sativum. CsA: Areal part of C.sativum. Results are presented as the mean \pm S.E. (Standard Error) $\left(\mathrm{n}=6\right.$ ). ${ }^{*} \mathrm{p} \leq 0.05,{ }^{* *} \mathrm{p} \leq 0.01$ and ${ }^{* * *} \mathrm{p} \leq 0.001$. ap $<0.05$ as compared with Lambda-cyhalothrin model group. ${ }^{\mathrm{b}} \mathrm{p}<0.05$ as compared with normal control group. 


\subsubsection{Histopathological examination of the liver}

The histologic examination of the liver section of the normal control group showed normal histologic picture of hepatic central vein and sinusoids (Figure 3). The liver sections of rats treated with Lambda-cyhalothrin alone showed inflammatory cells in the centrolobular zone and the necrosis of hepatocytes. It could also be observed that scattering penetrated inflammatory cells accumulated in liver sinusoids. Pre-administration of C.sativum extract (areal part and seed of plant) for 90 days could reduce the hepatic injury score.
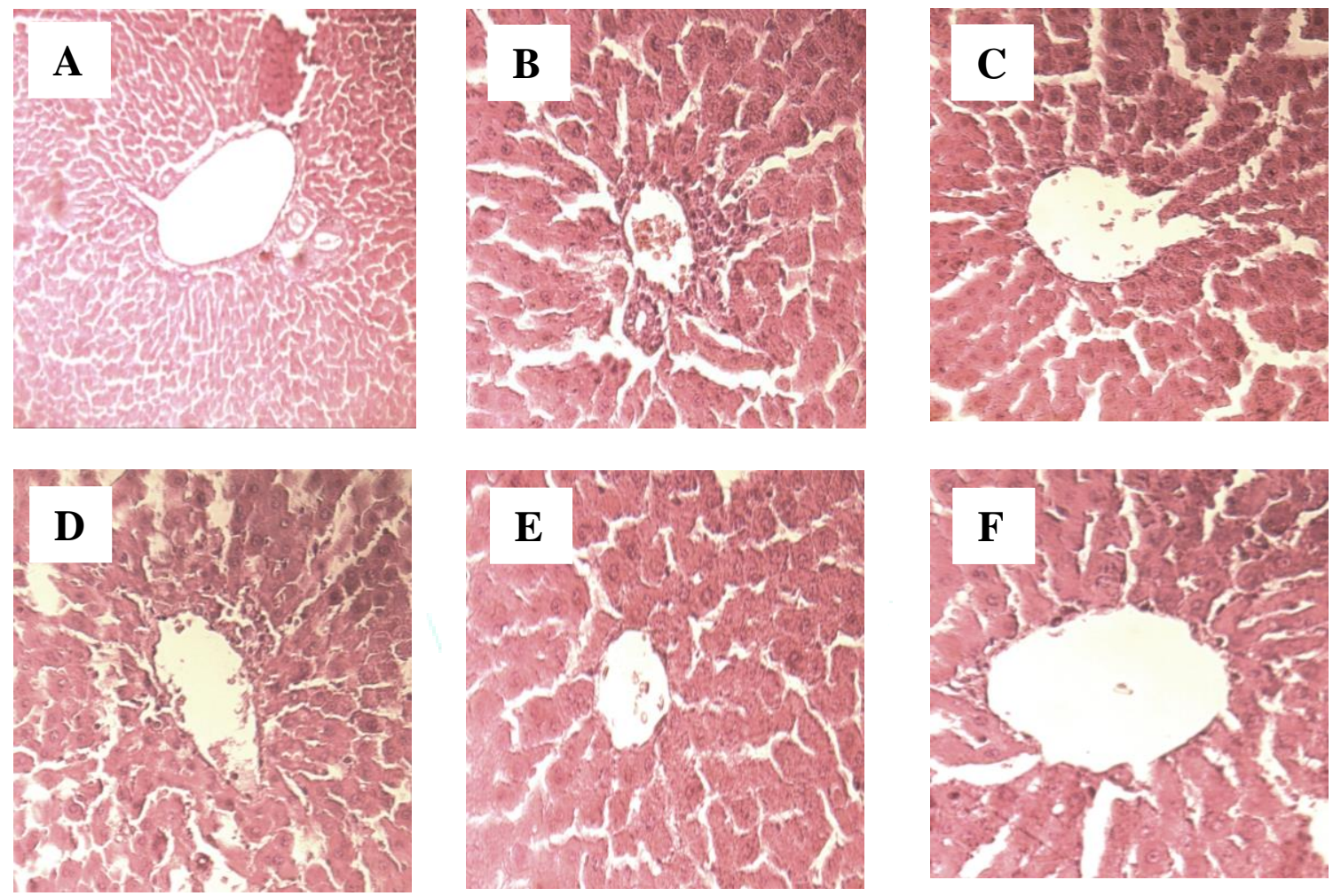

Figure 3: Histological examination of the liver section; normal control and other groups

A: Control. B: Lambda-cyhalothrin. C: Seed of C.sativum+Lambda-cyhalothrin. D: Areal part of C.sativum+Lambda-cyhalothrin. E: Seed of C.sativum. F: Areal part: of C.sativum (X40)

\section{DISCUSSION}

Antioxidant properties make coriander more useful to humans beyond just the use as a seasoning. It can be used as a natural antioxidant to help prolong the shelf-life of foods. Many diseases, such as atherosclerosis, dementia, diabetes, cancer, and inflammation, derive from ageing and an unhealthy modern lifestyle and nearly all of these are related to attack by reactive oxygen species (ROS). Coriander is able to help to reduce the oxygen stress and awaken the body's own antioxidase system, protecting the body from ROS attack. ${ }^{15}$. However, the extracts and essential oils of plant are used on food industry benefits as substitutes for chemical antioxidants 16 .

The present study was undertaken to investigate the antioxidant and hepatoprotective effect of areal part and seed of C.sativum extract against Lambda-cyhalothrin insecticide in Wistar rats. The $\mathrm{IC}_{50}$ value of areal part and seed of C.sativum as determined through DPPH $(1,1$ diphenyl-2-picry hydrazyl) free radical scavenging activity, our results are exhibited better antioxidant potency of areal part extract ( $\mathrm{IC}_{50} 19.38 \pm 0.14 \mu \mathrm{g} / \mathrm{mL}$ ) than seed extract ( IC $_{50}$ $22.62 \pm 0.04 \mu \mathrm{g} / \mathrm{mL}$ ) this results in agreement with research conducted by Sultana et al ${ }^{17}$ which was demonstrated that both methanolic crude extract of C.sativum found to be IC $_{50}$ $58.36 \mu \mathrm{g} / \mathrm{mL}$ ). To our knowledge, the antioxidant activities of this plant due to presence of some phenolics such as linalool, geranyl acetate and $\alpha$-pinene 18 .

Exposing Wistar rats to Lambda-cyhalothrin insecticide for 90 days increased the relative liver weights significantly compared to the control group. The increase in liver relative weight indicates a hepatomegaly caused by Lambdacyhalothrin, This liver anomaly is a phenomenon result of accumulation by chemicals 19 . The administration of C.sativum areal part with Lambda-cyhalothrin caused significant decrease in liver relative weight less than the control, which can indicate the hepatoprotective activity.

Concerning enzymes activity, the present data showed that a significant elevation of all investigated enzymes in both serum. Instead, serum ALT, AST and ALP activities were significantly inhibited after treated with C.sativum extracts, indicating predictive of effectiveness of C.sativum extracts in liver regeneration after damaged. In addition, the serum enzymes TGO, TGP, PAL and $\gamma$-GT are synthesized at cell cytoplasm and discharged into the circulation in case of damaged cells 20,21. These enzymes considered the best indicators of hepatic parenchyma cytolysis, which source from cell membrane and mitochondrial damages in liver cells. For example, high levels of liver enzymes, such as AST and ALT are frequently attributed to the metabolic of different toxic drugs such as psychotropic drugs 22 , alcohols 23 , Pollutants ${ }^{24}$ notably Lambda-cyhalothrin. 
Results from the present study demonstrate that the levels of endogenous antioxidants GSH are significantly decreased in the Lambda-cyhalothrin-treated group compared to the normal control rats, GSH is one of the abundant tripeptides, widely distributed in hepatocytes. Its functions are concerned by the displacement of free radicals such as $\mathrm{H}_{2} \mathrm{O}_{2}$ and superoxide radicals 25 . Furthermore, GSH is the first line of defence system that protects the cell from the deleterious effects of reactive oxygen species 26. Previous studies indicated that GSH capable of recuperating superoxide anions and the hydroxyl radical by giving it electrons and becoming oxidized to their radical 27 .

There are some effective defense mechanisms to protect against damage induced by free radicals. These mechanisms are ensured by the use of endogenous antioxidant enzymes such as: MDA, GST, CAT, SOD, ... etc. against oxygen reactive species ${ }^{28}$. The results obtained indicate increased MDA levels in response to Lambda-cyhalothrin treatment, implying increased oxidative damage to the liver. However, there are some authors reported that the oxidation of fatty acids in the cell membrane results the formation of MDA, which is considered an indicator of lipid peroxidation; can be evaluated by high rates of MDA ${ }^{29}$. Also, Kyle et al ${ }^{30}$ stated that the increase in enzyme activitie was probable a response towards increase Reactive Oxygen Species (ROS) generation. Generally, Our results demonstrate a very good protective effect of C.sativum extract against Lambdacyhalothrin - induced perturbation in the levels of endogenous antioxidants both enzymatic and non-enzymatic (GSH and MDA) , which is probably due at least partly to its antioxidative properties, scavenging Lambda-cyhalothrin associated free radicals.

The presence of injuries in livers of Lambda-cyhalothrin treated rats was revealed by histopathological examinations. In case of control group showed normal hepatic central vein, sinusoids and normal architecture of hepatocytes. The liver sections of rats treated with Lambda-cyhalothrin alone showed hepatocytes necrosis, local inflammation around the central vein and destruction of vascular walls. Pretreatment of C.sativum extracts reduced the severity of Lambdacyhalothrin induced liver intoxication. Liver parenchyma was well preserved with radially arranged hepatocytes around the central vein for both groups. Regular sinusoidal structures were reserved. The result of the histologic examination experiment is in concordance with biochemical result, which clearly indicate the hepatoprotective effects provided by plant natural products 21,31 .

\section{CONCLUSION}

The data of the present study suggests that C.sativum had a hepatoprotective effect against Lambda-cyhalothrin insecticide-induced hepatic damage in rats. Contributing to the alleviation of Lambda-cyhalothrin triggered typical hepatotoxic characterization. Obtained results show that the C.sativum can be used as source of natural antioxidants and as a possible food supplement. The hepatoprotective effect of C.sativum is likely due to its ability to scavenge free radicals, suppress the inflammatory responses and improve drug-metabolizing enzyme activity.

\section{ACKNOWLEDGEMENT}

We would like to express our deepest appreciation to all those who provided the help for realisation of this research.

\section{Conflict of interest statement}

The authors report no conflict of interest.

\section{REFERENCES}

[1] Gurpreet K, Sarwar Alam M, Zoobi J, Kaleem J, Mohammad A. Evaluation of antioxidant activity of Cassia siamea flowers. J.Ethnopharmacol 2006; 108:340-348.

[2] Shaker ME, Zalata KR, Mehal WZ, Shiha GE, Ibrahim TM Comparison of imatinib, nilotinib and silymarin in the treatment of carbon tetrachloride-induced hepatic oxidative stress, injury and fibrosis. Toxicol. Appl. Pharmacol 2011; 252:165-175.

[3] Gachkar L, Yadegari D, Rezaei MB, Taghizadeh M, Astaneh SA, Rasooli I. Chemical and biological characteristics of Cuminum cyminum and Rosmarinus officinalis essential oils. Food Chem 2007; 02:898-904.

[4] Muthamma Milan KS, Dholakia H, Kaultiku P, Vishveshwaraiah P. Enhancement of digestive enzymatic activity by cumin (Cuminum cyminum L.) and role of spent cumin as a bionutrient. Food Chem 2008; 110(3):678-683.

[5] Cazzi R, Ricardy R, Aglitti T, Gatta V, Petricone P, De Salvia R. Ascorbic acid and b-carotene as modulators of oxidative damage; Carcinog 1997; 18:223-228.

[6] Vitaglione P, Morisco F, Caporaso N, Fogliano V. Dietary Antioxidant compounds and liver health. Crit Rev Food Sci Nutr 2004; 44(78):575-86.

[7] Bouquet A. Plantes médicinales du Congo-Brazzaville; Uvariopsis, Pauridiantha, Diospyros ... Paris, Ed: O.R.S.T.O.M. 1972: No. 13.

[8] Li HB, Cheng KW, Wong CC, Fan KW, Chen F, Jiang Y. Evaluation of antioxidant capacity and total phenolic content of different fractions of selected microalgae. Food Chem 2007; 102:771-776.

[9] Singleton VL, Rossi JA. Colorimetry of total phenolics with phosphomolybdic phosphotungstic acid reagents. Am J Enol Viticult 1965; 16:144-158.

[10] Mansouri A, EmbarekG, Kokkalou E, kefalas P. Phenolic profile and antioxidant activity of the Algerian ripe date fruit (phonix dactylifera). Food Chem 2005; 89:411-420.

[11] Torres R, Faini F, Modak B, Urbina F, Labbe' C, Guerrero J. Antioxidant activity of coumarins and flavonols from the resinous exudate of Haplopappus multifolius. Phytochemistry 2006; 67:984-987.

[12] Bradford MM. A rapid and sensitive for the quantitation of microgram quantities of protein utilizing the principle of protein-dye binding. Anal. Biochem 1976; 72:248-254.

[13] Weckbercker G, Cory JG. Ribonucleotide reductase activity and growth of glutathione-depleted mouse leukemia L1210 cells in vitro. Cancer Letters 1988; 40(3):257-264.

[14] Quintanilha AT, Packer L, Davies J MS, Racanelli TL, Davies KJA Membrane effects of vitamin E deficiency: bioenergetic and surface charge density studies of skeletal muscle and liver mitochondria. Ann. N. Y. Acad. Sci. 1982; 393:32-47.

[15] Wei TY, Hsueh PH, Wen SH, Chen CL, Wang CC. The Role of Tea and Coffee in the development of gastroesophageal reflux disease, Tzu Chi Medical Journal 2019; 31(3):169-176.

[16] Marangoni C, Moura, NF. Antioxidant activity of essential oil from Coriandrum Sativum L. in Italian salami. Ciencia Tecnol Alime 2011; 31(1):124-128.

[17] Sultana S, Ripa FA, Hamid K. Comparative antioxidant activity study of some commonly used spices in Bangladesh. Pakistan J Biol Sci 2010; 13(7):340-343.

[18] Mageed MAAE, Mansour AF, El Massry K.F, Ramadan M.M Shaheen M.S, Shaaban H., Effect of microwaves on essential oils of coriander and cumin seeds and on their antioxidant and antimicrobial activities. J Essent Oil Bear Pl 2012; 15(4):614627.

[19] Huang QF, Zhang SJ, Zheng L, Huang RB, Lin X. Hepatoprotective effects of total saponis isolated from Tarathochlamys affinis against carbon tetrachloride induced liver injury in rats. Food Chem Toxicol 2012; 50:713-718.

[20] Singh B, Saxena AK, Chandan BK, Anand KK, Suri OP, Surisatti KA, Surisatti NK. Hepatoprotective activity of verbenalin on experimental liver damage in rodents. Fit 1998; 69:134-140.

[21] Ozturk IC, Ozturk F, Gul M, Ates B, Cetin A. Protective effects of ascorbic acid on hepatotoxicity and oxidative stress caused by carbon tetrachloride in the liver of Wistar rats. Cell Biochem Funct 2009; 27:309-315.

[22] Himmerich H, Kaufmann C, Schuld A, Pollmacher T. Elevation of liver enzyme levels during psychopharmacological treatment is associated with weight gain. J Psychiatr Res 2005; 39: 35-42. 
[23] Liappas I, Piperi C, Malitas PN, Tzavellas EO, Zisaki A, Liappas AI, Kalofoutis CA, Boufidou F, Bagos P, Rabavilas A. Interrelationship of hepatic function, thyroid activity and mood status in alcohol-dependent individuals. Toxicology 2006; 20: 293-300.

[24] Michailova A, Kuneva T, Popov TA. Comparative assessment of liver function in workers in the petroleum industry. Int. Arch. Occup. Environ. Health 1998; 71:46-49.

[25] Fang J, Sawa T, Maeda H. Factors and mechanism of EPR effect and the enhanced antitumor effects of macromolecular drugs including SMANCS. Adv Exp Med Biol 2003; 519:29-49.

[26] Ogeturka M, Kusa I, Colakoglub N, Zararsiza I, Ilhanc N, Sarsilmaz M, Caffeic acid phenethyl ester protects kidneys against carbon tetrachloride toxicity in rats. J. Ethnopharmacol 2005; 97:273-280.

[27] Franco R, Panayiotidis MI, Cidlowski JA. Glutathione depletion is necessary for apoptosis in lymphoid cells independent of reactive oxygen species formation. Journal of biological chemistry 2007; 282(42):30452-30465.

[28] Venukumar MR, Latha MS. Antioxidant activity of Curculigo orchioides in carbon tetrachloride-induced hepatopathy in rats. $J$ Clin Biochem 2002; 17:80-87.

[29] Weber LWD, Bool M, Stampfl A, Hepatototoxicity and machenism of action of haloalkanes: carbon tetrachloride as a toxicological model. Crit Rev Toxicol 2003; 33:105-136.

[30] Kyle ME, Miccadei S, Nakae D, Farber JL. Superoxide dismutase and catalase protect cultured hepatocytes from the cytotoxicity of acetaminophen. Biochem. Biophys. Res. Commun 1987; 149:889-896.

[31] Zeghib K, Djahra AB. Protective role of aqueous extract of Atriplex halimus L. Against benzene-induced damage on renal function and glomerular cells in rats. Asian J Pharm Clin Res 2019; 12(3):387-392. 